\title{
The Development of Bamboo Basketry According to the Base of Creative Economy of the Thai Yo Ethnic Group in Northeast Thailand
}

\author{
Bangchongsak Upphapong ${ }^{1}$, Sittisak Champadaeng ${ }^{1} \&$ Suchat Sookna $^{2}$ \\ ${ }^{1}$ Faculty of Cultural Science, Mahasarakham University, Muang District, Maha Sarakham, Thailand \\ ${ }^{2}$ Faculty of Fine Arts, Mahasarakham University, Khamriang Campus, Kanthawawichai, Maha Sarakham, \\ Thailand \\ Correspondence: Bangchongsak Upphapong, Faculty of Cultural Science, Mahasarakham University, Muang \\ District, Maha Sarakham 44000, Thailand. E-mail: banjonsaks@hotmail.com
}

Received: May 9, 2013 Accepted: May 30, 2013 Online Published: August 1, 2013

doi:10.5539/ass.v9n10p231 URL: http://dx.doi.org/10.5539/ass.v9n10p231

\begin{abstract}
The Thai Yo ethnic group have their great skill to make bamboo basketworks for household use and domestic distribution but for international distribution they should develop their products. This research suggests the ways to develop the products. A qualitative research was applied to the research and research data was gathered by means of a document analysis and a field study. Research areas were selected by a purposive sampling in the area of 3 provinces located in the northeast Thailand consisting of Kalasin, Sakon Nakhon, and Nakhon Phanom. Findings indicated that a majority of Thai Yo village located in the locations where were near water resources and bamboo basketworks but the difficulties were they just mastered making them in the old way and the products they made could not respond various requirements of customers, and those products needed an improvement. The six aspects used for developing the products were these: 1) balance, 2) proportion, 3) harmony, 4) contrast, 5) rhythm and 6) emphasis. These aspects gathered from opinions of persons concerned within a concept of creative economy.
\end{abstract}

The six models of bamboo basketworks were designed and made as the pilot models in order to guide the organizations concerned for developing their bamboo basketwork products to quality products.

Keywords: Thai Yo ethnic group, bamboo basketry, bamboo basketworks, creative economy, domestic distribution, international distribution

\section{Introduction}

Bamboo basketry or the art of weaving basket works by using bamboo strips of each ethnic group in Thailand reflects through bamboo basketworks. A wide variety of basketworks sold in domestic markets comes from several production villages in all parts of Thailand. This supports that each ethnic group living in Thailand has its own identity in bamboo basketwork production.

Several pieces of found evidence point out that humans knew how to make bamboo basketworks for a long time. Some examples of the evidence are a discovery of four thousand-year-old bamboo basketworks of people living in the new stone age in a cave where was in Sisawat District of Kanchanaburi Province; a discovery of potteries buried in the ground at the prehistoric civilization area of Ban Chiang, Udontani Province which their surfaces were stamped with the patterns of bamboo basketworks, both the aforementioned were discovered in Thailand; and another discovery in Iraq is a discovery of potteries at Ur, the one part of the Mesopotamia Kingdom, their surfaces also were stamped with the patterns of bamboo basketworks (Leesuwan, 1989: 1-2). Bamboo basketworks are basic daily utensils which general Thai people know and use. They are made of local bamboo strips by means of interweaving. Form of them depend on their functions, religious beliefs, and local traditions (Sirithong, 1999: 1). The progress of technologies affect the use of basketworks. Since new materials such as plastic, nylon, and polyester are used for making utensils, the utensils made of synthetic material are easy to buy, to use and to clean, including they are very cheap so general people tend to use them instead of bamboo basketworks as their own cultural identity. At present, many countries tend to process their economic promotion policy according to the concept of creative economy, this economic system gives a chance for all creative sectors to participate in an economic push by using national asset such as history civilization, culture, historical tourist 
sites and handicrafts, as economic catalysts. Thailand has a lot of national asset so when they are integrated with creativity, information and modern technology, it will be a strong economic base of the country (Rangkham, 2011: 4).

A group of Thai Yo living in northeast Thailand is the ethnic group who came from Kham Kird Kham Muan, the town located in the left bank of the Mekhong River in Laos. This ethnic group settled in the provinces of Sakon Nakhon, Nakhon Panom, Kalasin and Maha Sarakham. They selected the locations where had water sources such as swamps, lakes or rivers in order to use water for facilitating their ways of life which were related to agriculture and fishery. Almost Thai Yo people have great skill to make bamboo basketworks, some made for fishery, some made for agriculture, and some made for daily life use (Leesuwan, 1989: 63). At present, Thai Yo people still maintain their traditions and culture in the proper way. Bamboo basketworks are important products of Thai Yo communities especially the basketworks produced from the six villages of research area.

The main difficulties of bamboo basketwork of the Thai Yo people are lack of bamboo woods in the production villages resulted from people use them intensively and no replantations, including lack of designers who design new styles of bamboo products in order to get along with real requirements of customers and the developed products should be distributed to both domestic and international markets. Moreover, most countries in the world tend to set their economic policy according to the base of creative economy and give a chance for all creative persons to participate in economic reinforcement by using all national assets and integrating them with human creativity, information, and modern technologies.

Bamboo basketworks made from the Thai Yo villages in northeast Thailand are accepted by general people in terms of they have their own identities, especially their particular patterns and forms. The Thai Yo people are careful to select bamboo trunks for making their basketworks, the man who is in charge of bamboo selection always chips a sample part of one trunk of the target lump sway and touches his finget on the tissue coated inside the sample chip and then he tastes it, if its taste is sweet, it indicates that the bamboo lump can be used for making basketworks. Bamboo-basketwork producers always cut bamboo lumps in late winter or summer but they do not cut them in rainy season because that is the period of bamboo growth. Some part of indigenous knowledge concerning bamboo basketry of the Thai Yo ethnic group was gathered from the replies of the bamboo basketwork producers living in the research area.

\section{Research Aims and Methodology}

The aims of this research were these: 1) to investigate the background of bamboo basketry based on indigenous knowledge of the Thai Yo ethnic group living in northeast Thailand, 2) to investigate current situations and difficulties of bamboo basketry of the Thai Yo ethnic group living in northeast Thailand, and 3) to develop bamboo basketry of the Thai Yo ethnic group living in northeast Thailand according to the base of creative economy.

The researchers selected the areas where the Thai Yo living in and they were the areas of intensive bamboo basketwork production. Ban Phon Sim, Ban Sa of Kalasin Province; Ban Nong Ma Kluea, Ban Lao Por Daeng of Sakon Nakhon Province; and Ban Kham Phi, Ban Chomsi of Nakhon Phanom Province were selected by means of a purposive sampling technique.

A method of qualitative research was used for this research. The researchers gathered research data from both a document analysis and a field study. Participatory and non-participatory observation, in-depth interviews, focus group discussions, and workshops were used for searching findings throughout the research period.

The data gathered from statements of a sample consisted of a group of key-informants, a group of bamboo basketwork producers, and a group of general informants was examined by means of a triangulation technique. Research results were presented according to research aims by means of descriptive analysis.

\subsection{Research Framework}

The researchers conducted a research framework as the following: 


\section{Surveying feasible areas for researching}

2. Selecting the research area

3. Selecting the data concerned

4. Operating a field study in the research area

5. Gathering research data from a field study

6. Examining research data

7. Analyzing and interpreting research data

8. Presenting research results

9. Reporting research results

\subsection{Importance of the Research}

These research results will benefit organizations concerned and can be used as a model of product development according to the base of creative economy for the Thai Yo ethnic group in other parts of Thailand. Since a competition at an international level needs perfection of product, the bamboo basketworks of the Thai Yo ethnic group should also be developed.

\section{Results}

The research results have revealed the following:

1) In terms of the background of bamboo basketry based on indigenous knowledge of the Thai Yo ethnic group living in northeast Thailand, it originated from a majority of Thai Yo villages located in the locations where were near water resources and bamboo woods so they could use parts of bamboo trees for making things such as utensils, furniture, and fences, the great skill to make bamboo basketworks resulted from their hard practice, including this knowledge has been transmitted from generations to generations.

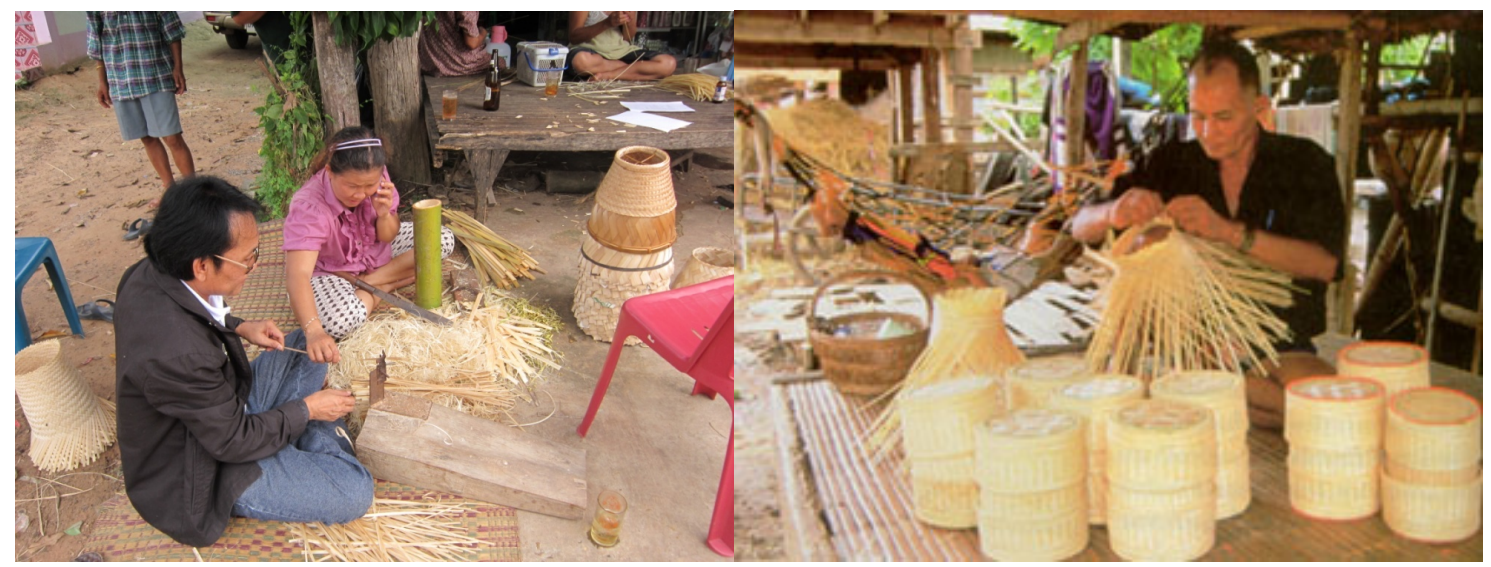

Figure 1. Indigenous knowledge on making bamboo basketworks transmitted from generation to generations

2) In terms of current situations and difficulties of bamboo basketry of the Thai Yo ethnic group living in northeast Thailand; at present, some producers use machines for spitting bamboo into fine strips but some still use spitting knives so it has many differences in production standards, a majority producers still maintain ancient patterns, forma and production of basketworks as the way they were in the past so the difficulties are a limitation of forms, a lack of creative designers, and a lack of budget for business extending. 


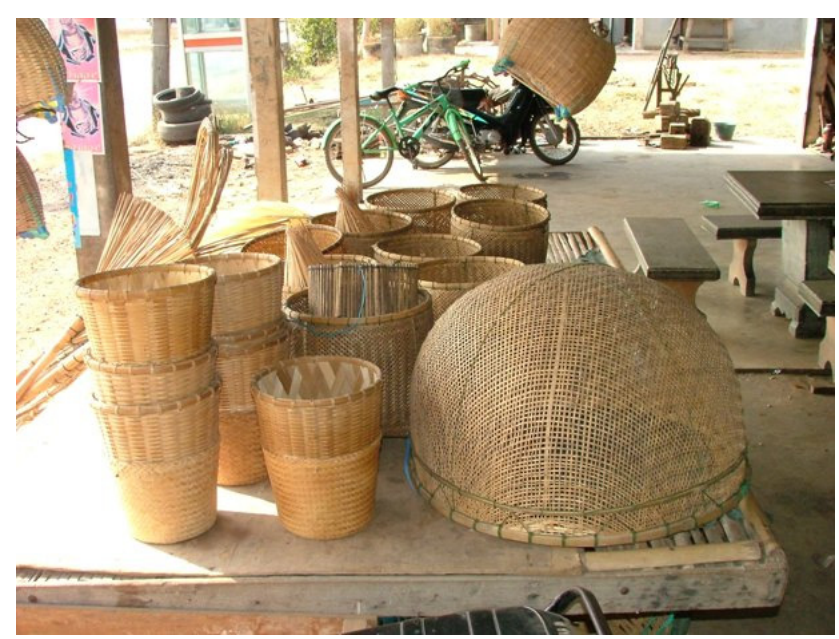

Figure 2. Ancient patterns and forms of basketworks

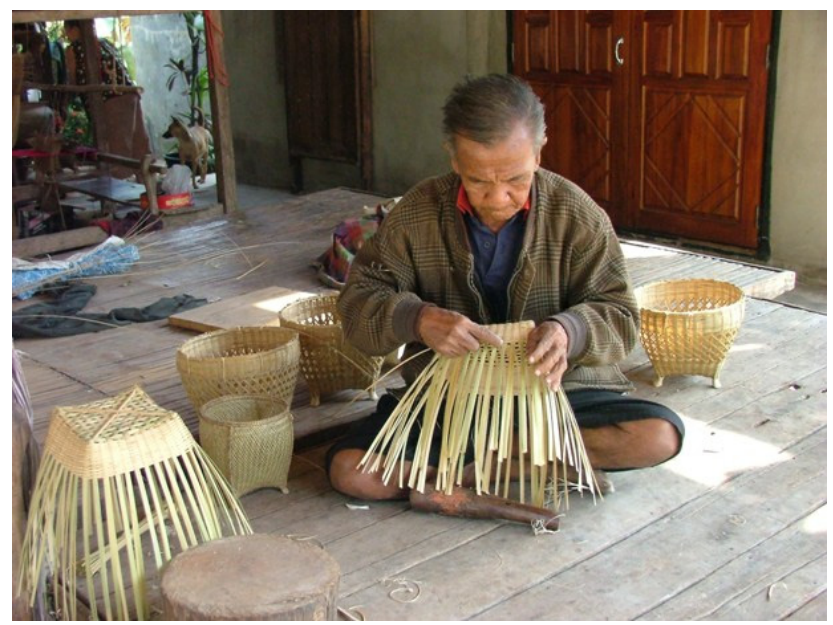

Figure 3. A majority of bamboo basketwork producers still maintain the old method of production

3) In terms of the development of bamboo basketry of the Thai Yo ethnic group living in northeast Thailand according to the base of creative economy; the target producers develop their bamboo basketworks into 6 aspects: a) balance b) proportion c) harmony d) contrast e) rhythm and f) emphasis, the six model bamboo basketworks in order to be compatible with a current collective lifestyle of general people.

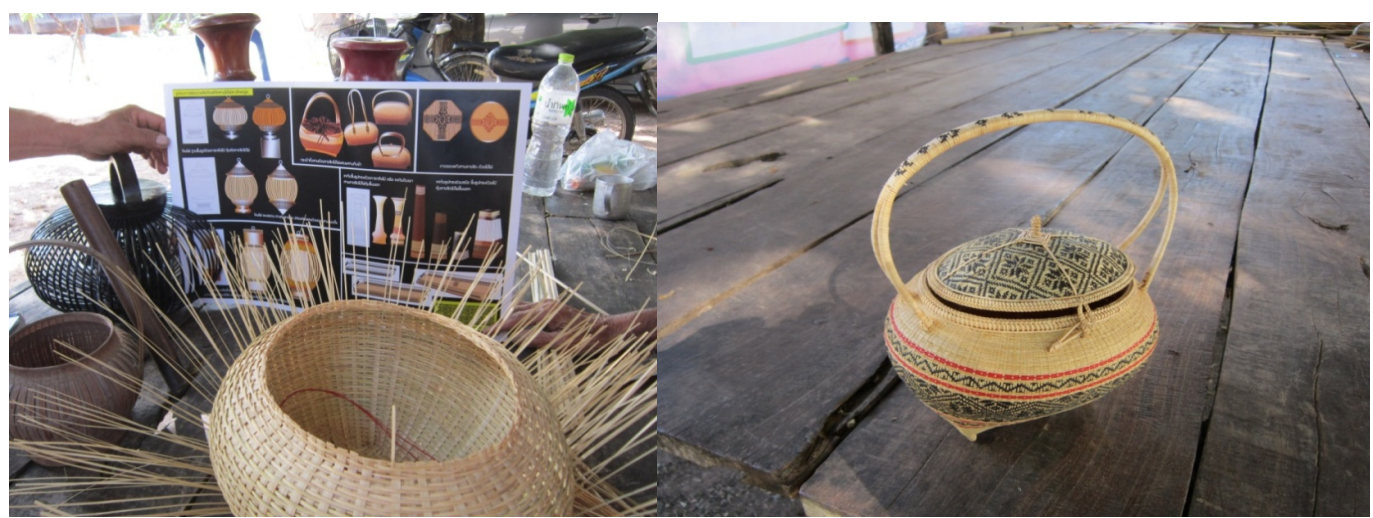

Figure 4. Some samples of the developed bamboo basketworks designed by using the principles of balance, proportion, harmony, contrast, rhythm and emphasis 


\section{Discussion}

According to the results, the researchers would like to discuss them as follows: Since the majority of Thai Yo villages located in the locations where were near water resources and bamboo woods so almost ancestors of them had a chance to develop their skill in making basketworks and then when they mastered it, they handed down to descendants and relatives, this knowledge has been transmitted from generations to generations as cultural heritage. Nowadays, it becomes the great skill of this ethnic group. The background of bamboo basketry based on indigenous knowledge of the Thai Yo ethnic group living in northeast Thailand is consistent with anthropologist Julian Steward (1972), he hypothesizes that resource exploitation gives rise to the social systems that exist in a specific location and the resource exploitation of a society is determined by the technological adaptations that people make to their surrounding environment. Moreover, it is consistent with the concept of "Community Culture" of the Office of National Culture Commission (n. d.), which defines that community culture is a part of core culture and an identity of each community, the community should conserve and perpetuate it as community's strength, including use it as cultural resource for promoting community economy according to the concept of creative economy. At present, the majority of producers still use ancient tools and methods for producing bamboo basketworks but some who produce them for commercial purpose use machines for splitting bamboo into fine strips, the machines help them in terms of increasing productivity and standardization, almost bamboo basketwork makers are the elderly. They make them for their household use and customer's orders during the time that is out of farm work. The bamboo basketworks which they made will be sent to the community-product center of each production group in order to sell at the center or distribute to dealers. When demands of bamboo basketworks are on the increase, bamboo trees in production each production area are reduced and producers must buy them from other sources so it causes high production costs and low profits, a lack of budget for extending business is the main difficulty of producers. When they encounter with a lack of budget, they have no enough money for developing their products which can serve real requirements of customers so they cannot built up value added on their interest in bamboo products. This is consistent with Marut Amnanon (1990: 124), he writes that some villages have no bamboo-basketwork makers who make household utensils for their household use, the advantages of plastic products are very cheap and easy to buy.

The ways to develop bamboo basketworks of the Thai Yo ethnic group living in northeast Thailand according to the base of creative economy had retrieved from the participative workshop held by persons concerned led to the product improvement of the target producers. The six-model bamboo basketworks of the six villages from the tree provinces had been improved in 6 aspects according to the standards of community products: a) balance, b) proportion, c) harmony, d) contrast, e) rhythm and f) emphasis. These aspects were analyzed from a set of current-collective lifestyle of general people. These ways may help bamboo-basketwork producers in terms of building value added on their products and enhancing product interest. This is consistent with Cinnarat Somsueb (1996: 18-19) who writes that all processes of community development need the cooperation of all sectors especially the development by using community culture as a catalyst for growth in economy and tourism. This case is consistent with Sonchai Ritthichot (1996: 70-75) who writes that there are many ways to create new functions of product from its traditional functions; for example adding new functions to the product which its old form is maintained, adding new functions to new product which is developed from old product, and creating new functions to new product which is designed for new purposes. It is also consistent with Anuchit Kunmala (2009: 422-427) who studied about the ways to develop local bamboo basketwork products for increasing commercial value added in the provinces of the lower north Thailand, the results have revealed that there are two ways to develop bamboo basketwork products: a) developing them according to the standards of community products such as changing their designs, their forms and their sizes for serving customers' requirements, boiling bamboo strips in hot mixture of water, salt and alum in order to make strength for them and protect them from fungi and wood borers, using local patterns decorate on them, weaving them with dyed bamboo strips which have a shade of monochrome color, b) developing them according to the summary from the workshop such as creating them as local products which have their own identity likes the products ancestors made, adding new functions to the old products, decorating them with local patterns for making cultural identity, and focusing on the quality of product.

Furthermore, some truths which the researchers found in the research area have revealed that some people tend to use plastic ware in their daily life for a reason still remain use and make bamboo basketworks as the same way of their ancestors. Making and using bamboo basketworks is cultural identity of the Thai Yo people, this indigenous knowledge has been transmitted from generations to generations and it is written in curriculums of many schools. Developing these products according to the base of creative economy is very important because the current trend of economic policy of most countries in the world is creative economy. Thus, designers and 
producers should cooperate in the production process of bamboo basketworks in order to have products which respond requirements of both domestic and international customers. The six developed models of bamboo basketworks were designed by using the principles of balance, proportion, harmony, contrast, rhythm, and emphasis. These models can use as the models of product development of organizations concerned. This product development is consistent with Chawiwan Khaikrathok (2008: 418-420) who studied about the application of indigenous knowledge for developing bamboo products into commercial products in Nakhon Ratchasima, the result has revealed that bamboo-product producers must develop their products into commercial products in three ways: a) developing bamboo utensil products into decorative products; for example, Kra Tib Khao (sticky-rice boxes) were adapted to savings banks, vases, hanging vases, toy-boxes, pencil boxes, and handkerchief-boxes, b) developing bamboo traps and cages into miniature products; for example, Sai (fish traps) were adapted into decorative objects in living room, and souvenirs for wedding and housewarming, and c) developing bamboo musical instruments into miniature products; for example, Can (reed mouth organs) and Wot (steam whistles) were adapted into bunches of keys, souvenirs, and decorative objects in living room or meeting room.

\section{Conclusion}

Promoting bamboo basketwork products of the the Thai Yo ethnic group should manage them according to the concept of developing community enterprise which focus on self reliance, all members of community should participate in all activities in order to build sustainable economy and social solidarity. The self reliance will lead community grows and solidarity of community is strong.

\section{References}

Ammaranon, M. (1990). Local Arts. Chonburi: Faculty of Social Science and Humanities, Burapha University.

Khaikrathok, C. H. (2008). The Application of Indigenous Products in Nakhon Ratchsima. Master Degree Dissertation, Maha Sarakham: Mahasarakham University.

Kunmala, A. (2009). A Study of the Ways to Develop Local Bamboo Basketwork Products for increasing Commercial Value Added in the Provinces of the Lower north Thailand. Doctoral Dissertation, Maha Sarakham: Mahasarakham University.

Leesuwan, W. (1989). "Basketworks in Thailand," in Local Culture: Fine Arts. Bangkok: Chulalongkorn Unoversity.

Office of National Culture Commission. (n. d.). Culture and Local Culture. Bangkok: Office of National Culture Commission.

Raengkham, K. (n. d.). Seminar Document on the Useful Chance from Investment Freeing Under AEC/FTA. June 15, 2013.

Ritthichote, S. (1996). Products Made of Bamboo-Rattan. Bangkok : Odian Store.

Sirithong, B. (1999). Bamboo Partition Weaving at Ban Udom, Tambon Nong Phai, Amphoe Thawat Buri, Changwat Roi Et. Master Degree Dissertation, Maha Sarakham : Mahasarakham University.

Steward, J. H. (1972). Theory of Culture Change: The Methodology of Multilinear Evolution. University of Illinois Press.

\section{Copyrights}

Copyright for this article is retained by the author(s), with first publication rights granted to the journal.

This is an open-access article distributed under the terms and conditions of the Creative Commons Attribution license (http://creativecommons.org/licenses/by/3.0/). 